\section{Spontaneous abortion and NSAIDs}

Nakhai-Pour and colleagues ${ }^{1}$ reported a possible increased risk of spontaneous abortion associated with any type or dose of nonsteroidal anti-inflammatory drug (NSAID). This finding supports earlier work by Nielsen and colleagues ${ }^{2}$ - which is not surprising, given that a combination of population-based prescription drug registries and pregnancy outcome databases was used in both studies. A criticism of the design of the earlier study ${ }^{3}$ can also be made of the later study. Filling a prescription does not adequately represent actual use of the drug prescribed, thereby rendering the findings unreliable. Nakhai-Pour and colleagues ${ }^{1}$ do provide a reference that supports the validation of riskassessment studies using the Régie de l'assurance maladie du Québec prescription drug database for pregnant women, but the citation is from their own institution and includes one of their coauthors, ${ }^{4}$ thus raising the possibility that the validation is lacking the necessary degree of independence or objectivity.

The authors stated that "to their knowledge," neither smoking nor body mass index (BMI) are risk factors for spontaneous abortion and therefore neither needed to be considered as a confounding factor in their analyses. They cite their own work as the source for this statement. ${ }^{5}$ Not only maternal, but also paternal and environmental exposure to smoking have been reported to be associated with an increased incidence of spontaneous miscarriage. ${ }^{6}$

A recent meta-analysis of the effect of BMI on spontaneous abortion reported that patients with a BMI greater than $25 \mathrm{~kg} / \mathrm{m}^{2}$ have significantly higher odds of miscarriage regardless of the method of conception, ${ }^{7}$ and evidencebased guidelines for the investigation and treatment of recurrent miscarriage include BMI as a risk factor. ${ }^{8}$ NakhaiPour and colleagues ${ }^{1}$ were not able to ascertain the smoking and BMI status of their cohorts because of their study design, but we suggest that not considering these factors puts their findings further in question.

We believe that it would be interesting if the authors were to compare the obstetric histories and pre-existing comorbidities of the subgroup of women who filled prescriptions for nonaspirin NSAID and had a live birth $(n=1213)$ with the subgroup that filled the same prescriptions but had a spontaneous abortion $(n=352)$. This might reveal a distinct demographic at increased risk of miscarriage.

Because this was a population-based study, the authors were unable to assess usage of over-the-counter NSAIDs. In 2005, Werler and colleagues ${ }^{9}$ reported that the use of over-the-counter medications is extremely common during pregnancy. That an association between a common occurrence and a rare marker cannot be shown may be an epidemiologic truism. However, if an association between two common events, such as NSAID use and spontaneous abortion, exists it should be possible to find. A study is required that includes the use of both over-the-counter and prescription NSAIDs during pregnancy and, the analysis must control for all known confounding factors for each event. Until then, we are left with studies such as this one - that provide subsets of data that suggest an association but do not adequately support their claims.

\section{Christine A. Clark PhD \\ Karen A. Spitzer MSc \\ Carl A. Laskin MD}

University of Toronto and LifeQuest Centre for Reproductive Medicine, Toronto, Ont.

\section{Gideon Koren MD}

Hospital for Sick Children, University of Toronto, Toronto, Ont and University of Western Ontario, London, Ont.

\section{References}

1. Nakhai-Pour HR, Broy P, Sheehy O, et al. Use of nonaspirin anti-inflammatory drugs during pregnancy and the risk of spontaneous abortion. CMAJ 2011;183:1713-20.

2. Nielsen Gl, Sørensen HT, Larsen H, et al. Risk of adverse birth outcome and miscarriage in pregnant users of non-steroidal anti-inflammatory drugs: population-based observational study and casecontrol study. BMJ 2001;322:266-70.
3. Chan LY, Yuen PM. Risk of miscarriage in pregnant users of NSAIDs: more information is needed to be able to interpret study's results [letter]. BMJ 201;322:1365-6

4. Bérard A, Lacasse A. Validity of perinatal pharmacoepidemiologic studies using data from the RAMQ administrative database. Can J Clin Pharmacol 2009;16:e360-9.

5. Nakhai-Pour HR, Broy P, Berard A. Use of antidepressants during pregnancy and the risk of spontaneous abortion. CMAJ 2010;182:1031-7.

6. Blanco-Muñoz J, Torres-Sanchez L, LopezCarrillo L. Exposure to maternal and paternal tobacco consumption and risk of spontaneous abortion. Public Health Rep 2009;124:317-22.

7. Metwally M, Ong KJ, Ledger WL, et al. Does high body mass index increase the risk of miscarriage after spontaneous and assisted conception? A meta-analysis of the evidence. Fertil Steril 2008; 90:714-26.

8. Jauniaux E, Farquharson RG, Christiansen OB, et al. Evidence-based guidelines for the investigation and medical treatment of recurrent miscarriage. Hum Reprod 2006;21:2216-22.

9. Werler MM, Mitchell AA, Hernandez-Diaz S, et al.; National Birth Defects Prevention Study. Use of over-the-counter medications during pregnancy. Am J Obstet Gynecol 2005;193:771-7.

CMAJ 2011. DOI:10.1503/cmaj.111-2092

\section{The authors respond:}

We disagree with Clark and colleagues. ${ }^{1}$ Given that the use of nonsteroidal antiinflammatory drugs (NSAIDs) is on an acute basis, even when used for chronic conditions, women who took the time to go to the pharmacy most likely took at least one pill. Glover and colleagues ${ }^{2}$ have shown that most pregnant women who fill a prescription take it, and Daniels and colleagues ${ }^{3}$ have shown that self-reporting measures of medication use do not provide accurate measurements when compared with electronic monitoring, as was done in our study. ${ }^{4}$

Data on maternal smoking and body mass index (BMI) were available only for a subset of women included in our registry. However, these variables would need to confound the effect to bias our results. For smoking and BMI to be confounders, they would need to be associated with both outcome and exposure. Delaney and colleagues ${ }^{5}$ have shown that smoking and BMI are not associated with use of NSAIDs that are prescribed or over the counter.

The registry includes data on the use of prescription medication during gestation. We looked at over-the-counter ibuprofen obtained with a prescription; however, the number of women who used over-the-counter ibuprofen with- 